\title{
A COMPARISON OF TWO PLANTING SYSTEMS IN ORCHARDS AS REGARDS THE AMOUNT OF RADIATION INTERCEPTED BY THE TREES')
}

\author{
J. H. A. FERGUSON \\ Institute of Horticultural Plant Breeding, Wageningen, Netherlands.
}

\section{SUMMARY}

A method has been worked out, and applied under conditions at De Bilt, Holland, to compare the gross amount of global radiation received by orchard trees planted in different patterns. A single row planting system and a triangle-row system have been compared, each for various orientations of the rows. It appeared that under the single row system the orientation of the rows may considerably influence the amount of radiation received, in contrast with the triangle-row system, where the effect of orientation may be neglected. The effect is not the same in all months. In September the single rows running East-West yielded $9 \%$ more radiation than rows running North-South. Averaged over all orientations the amount of radiation received was the same for both planting systems.

An alternative, probably more simple method is described at the end of the discussion.

\section{INTRODUCTION}

A well known planting system in orchards is planting in single rows. Between the rows a tractor wide path is kept free.

H. J. BLAAS (manager of the experimental farm "De Santacker" of this Institute) suggests that a different planting system would be preferable in various respects. He proposes to form pairs of rows with less space between the rows, but with a greater distance between the trees in the rows, so that each pair of rows forms a row of triangles. Between each pair of rows a tractorwide path is kept free. The planting system would not affect the number of trees per hectare. One of his arguments is that in the latter system the trees would receive more light, i.e. more global radiation. To check this argument is the object of the present study. Moreover it seemed desirable to investigate whether the amount of radiation would be affected by the orientation of the rows in either system.

\section{Method}

The investigation has been performed by photographing models from different directions. The area of the image of a tree model on the photograph was used as a measure for the amount of radiation intercepted by the tree.

Two planting systems have been compared:

I. A single row-system; distance between the trees in the rows 3 meter and distance between the rows $4 \frac{1 / 2}{2}$ meter. Average surface per tree $13 \frac{1}{2} \mathrm{~m}^{2}$.

II. A "triangle-rows-system"; distance between the trees in the rows 4 meters and between the rows alternatively $2 \frac{1}{2} \mathrm{~m}$ and $4 \frac{1}{2} \mathrm{~m}$. Each tree is placed opposite the gap between trees in the next row. Average surface per tree $14 \mathrm{~m}^{2}$, which is $3.7 \%$ more than in system $\mathrm{I}$.

1) Received for publication August 12, 1960. 


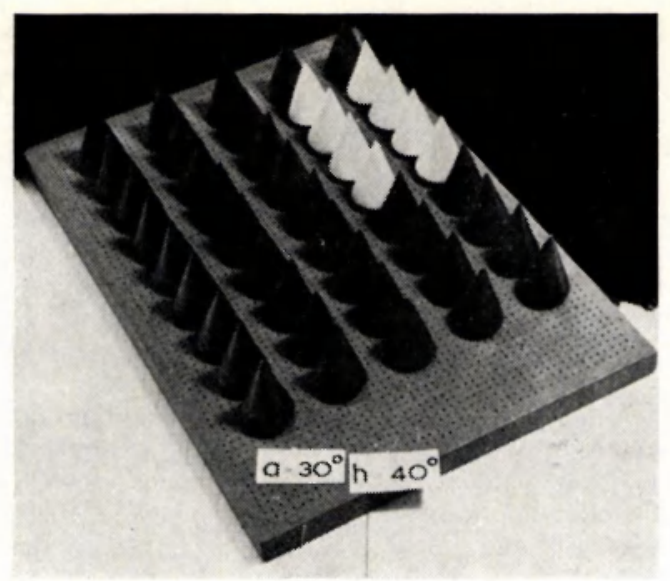

Fig. 1 Moder for planting System I.

The models consist of wooden cones (height $45 \mathrm{~mm}$ and diameter of the base $30 \mathrm{~mm}$ ) placed on boards. In the centre of the bases of the cones is a pin, on which the cones can stand on the board, in which small holes have been drilled. Each cone represents a tree on a 1: 100 scale, i.e. a tree $4 \frac{1}{2} \mathrm{~m}$ high and $3 \mathrm{~m}$ wide at the base. The base of the canopy is $1 / 2$ meter $(5 \mathrm{~mm}$ in the model) from the soil level.

For each of the two systems mentioned a model was made (see figure 1 and 2). Eight trees on each model are painted white, they represent the object of investigation. The dark coloured trees provide for the border effect. It is observed that the cast shadows in the photographs play no part in the investigation.

To be able to make photographs from various specified directions, the model boards were placed on a drawing table, which could revolve on a horizontal axis. In this drawing table a pin was inserted, which fitted into a hole, drilled in the underside of each of the model boards, just below the centre of the eight white cones. The camera (Rolleiflex) was mounted so that the objective

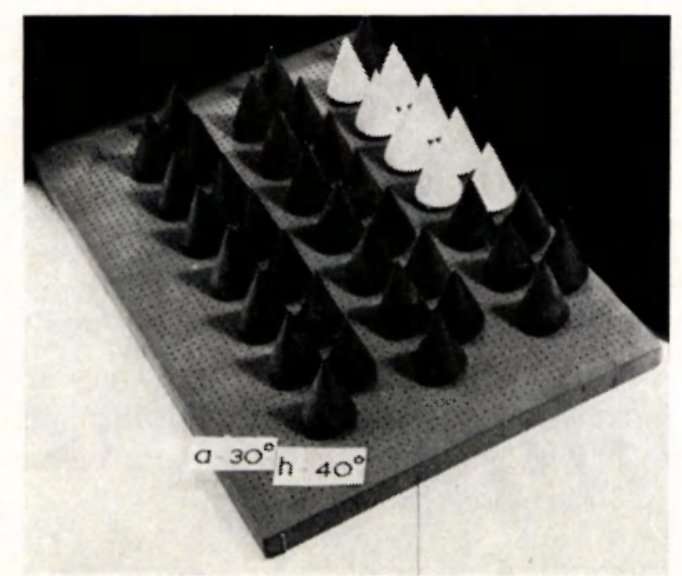

Fig. 2 MOdel. FOR PI.ANTING SYSTEM II. 
lens was $100 \mathrm{~cm}$ from the centre of the eight white tree-tops, on a horizontal line through this point, perpendicular to the horizontal axis of the drawing table.

The inclination of the drawing table represents the sun's altitude (h). Both models have been photographed under the altitudes:

$$
\mathrm{h}=10^{\circ}, 20^{\circ}, 30^{\circ}, 40^{\circ}, 50^{\circ} \text { and } 60^{\circ} \text {. }
$$

The angle between the direction of the rows and the direction of the camera, measured in the plane of the drawing table, represents the angle between the direction of the rows and the direction of the sun. Let this angle be a. For each of the sun's altitudes, h, mentioned above, the rows were placed at the angles

$$
\mathrm{a}=0^{\circ}, 15^{\circ}, 30^{\circ}, 45^{\circ}, 60^{\circ}, 75^{\circ} \text { and } 90^{\circ} \text {. }
$$

In each position a photo was made. Consequently the total number of photographs was 2 (planting systems) times 6 (sun's altitudes) times 7 (directions of the rows), i.e. 84. All photographs were enlarged on exactly the same scale.

On each photograph the total area of the eight white tree-images was measured by means of a polarplanimeter. From these areas it is possible to estimate, in comparative terms, the amount of direct solar radiation intercepted by the trees for a given position of the sun, and the amount of diffuse radiation from each sector of the clouded sky. Interpolation allows to make a good estimate of the comparative amount of radiation which the trees receive for each altitude of the sun and for each angle between the direction of the sun and the rows. Therefore this amount can be estimated for each date, each hour and each orientation of the rows. Under the amount of radiation we understand here the direct solar radiation and the diffuse global radiation intercepted by the trees, not accounting for reflection etc. This study is concerned with comparison of planting systems only, and therefore the relations between the resulting figures are of primary importance.

The outline of the computations is as follows: the areas of the images on the photographs are converted to the corresponding areas of their shadows on the ground, by dividing each image-area by the sine of the inclination under which the photo was taken. The amount of radiation intercepted by the trees would be the product of the shadow-area and the amount of radiation energy on unit horizontal area in unit time. The radiation energy on a horizontal area has been estimated by means of Angström's formula :

$$
\mathrm{Q}=\mathrm{Q}_{\mathrm{o}}[\alpha+(1-\alpha) \mathrm{p}]
$$

The values of the parameters $\alpha$ and $Q_{o}$ for daily one-hour periods, averaged for each month, have been derived from a study by DE BoER, who estimated these values from measurements in De Bilt (Netherlands) in 1954 to 1958 inclusive. The parameters stand for: $Q_{o}$ is the total global radiation in $\mathrm{cal} / \mathrm{cm}^{2}$ for unclouded sun during the hour periods considered; $\alpha$ is an empirical constant factor; $p$ is the fraction of the hour period with unclouded sun and $Q$ is the estimated total global radiation in $\mathrm{cal} / \mathrm{cm}^{2}$ during the hour period. The values of $p$, shown in Table 1, have been derived from C. BraAk (1937); they are valid for De Bilt as well, for the period 1899-1935 however. Although our conclusions have been based on data from De Bilt, the error of referring to them for the main fruit areas in the Netherlands is expected to be negligible. 


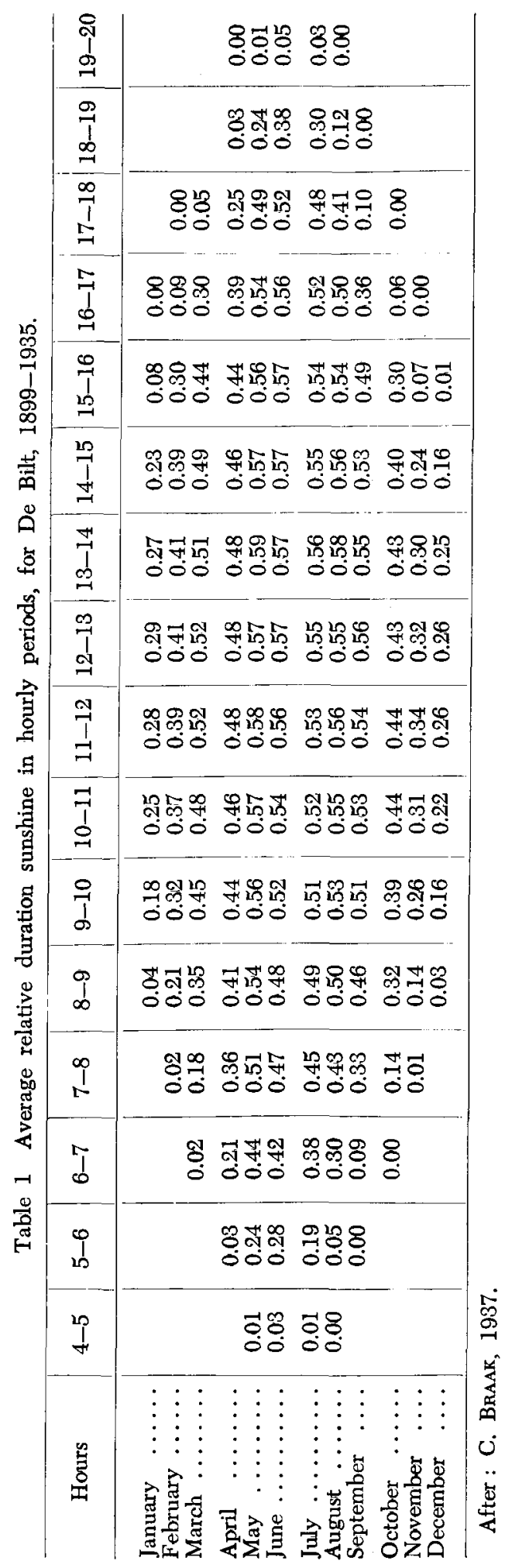









\section{Computations}

Angström's formula may be written in the form :

$$
\begin{gathered}
\mathrm{Q}=\mathrm{Q}_{\mathrm{o}}[\alpha+(1-\alpha) \mathrm{p}]=\mathrm{pQ}_{\mathrm{o}}+(\mathrm{l}-\mathrm{p}) \alpha \mathrm{Q}_{\mathrm{o}} \\
\text { Let } \mathrm{Q}_{\mathrm{z}}=\mathrm{p} \mathrm{Q}_{\mathrm{o}} \text { and } \mathrm{Q}_{\mathrm{H}}=(1-\mathrm{p}) \alpha \mathrm{Q}_{\mathrm{o}} \text {, then : } \\
\mathrm{Q}=\mathrm{Q}_{\mathrm{z}}+\mathrm{Q}_{\mathrm{H}},
\end{gathered}
$$

so that $Q$, the total global radiation, is taken as the sum of the radiation during the time the sun is not clouded and the diffuse global radiation of the sky during the time the sun is clouded. The mean values of $Q_{Z}$ and $Q_{H}$ and the average altitude of the sun in the hourly periods are shown in Table 2.

Although there is some diffuse radiation as well during the periods of unclouded sun, it has been assumed that $Q_{z}$ only comes from the direction of the sun. The component $Q_{H}$ has been assumed to originate with equal intensity from all parts of the sky-sector above the altitude of $5^{\circ}$.

As the radiation is given per square centimeter on a horizontal surface, the areas of the images on the photographs have been converted to the corresponding areas of the shadows on the ground, as mentioned before. It should be noted that the photographs are not parallel-projections. This discrepancy has to be corrected. The mean distance from the top of the tree-models to the lens was $100 \mathrm{~cm}$. The reduction of the image, however, depends on the distance from the surface of the tree-models to the lens, which is more than $100 \mathrm{~cm}$. The difference is a function of the inclination, $\mathrm{h}$, of the drawing table, which stands for the altitude of the sun. Let it be assumed that the distance from the centre of gravity of the cone-surfaces to the lens is the real distance to be corrected for. As the distance from the top to the centre of gravity is $3 \mathrm{~cm}$, the correctionfactor for the area of the image-surfaces is :

$$
c_{h}=\left(\frac{100+3 \sinh }{100}\right)^{2}
$$

The reduction of the surface on the photograph is 0.432 . Therefore the real surface of the shadow per tree-model $(F)$, as converted from the imagesurfaces on the photographs $(B)$ is :

$$
F=\left(c_{h} / 0.432 \sin h\right) B \text {, }
$$

in which $F$ and $B$ are expressed in $\mathrm{cm}^{2}$. The values of $F$ and $B$ are given in Table 3.

The diffuse radiation originates with equal intensity from all sections of the sky, as accepted before. Each point in the sky casts a shadow of the tree over the ground. To compute the amount of radiation received from the sky the mean area of these shadows has to be estimated. The first step is to average the shadow areas for each altitude of the sky, over all angles of orientation (a). The second step is to compute a weighted mean of the latter averages. The weights are found in the following way: let the total area of the sky be unity and let this area be partitioned by horizontal circles, having a specified altitude, then the fractions of the sky between two adjoining circles are the weights to be used. These fractions are shown below:

$\begin{array}{cccccc}\text { Partition of the sky : } & 5-15^{\circ} & 15-25^{\circ} & 25-35^{\circ} & 35-45^{\circ} & 45-55^{\circ} \\ \text { Fraction of the sky : } & 0.17 & 0.16 & 0.15 & 0.13 & 0.11 \\ 55-65^{\circ} & 65-75^{\circ} & 75-85^{\circ} & 85-90^{\circ} & \\ 0.09 & 0.06 & 0.03 & 0.00 & \end{array}$




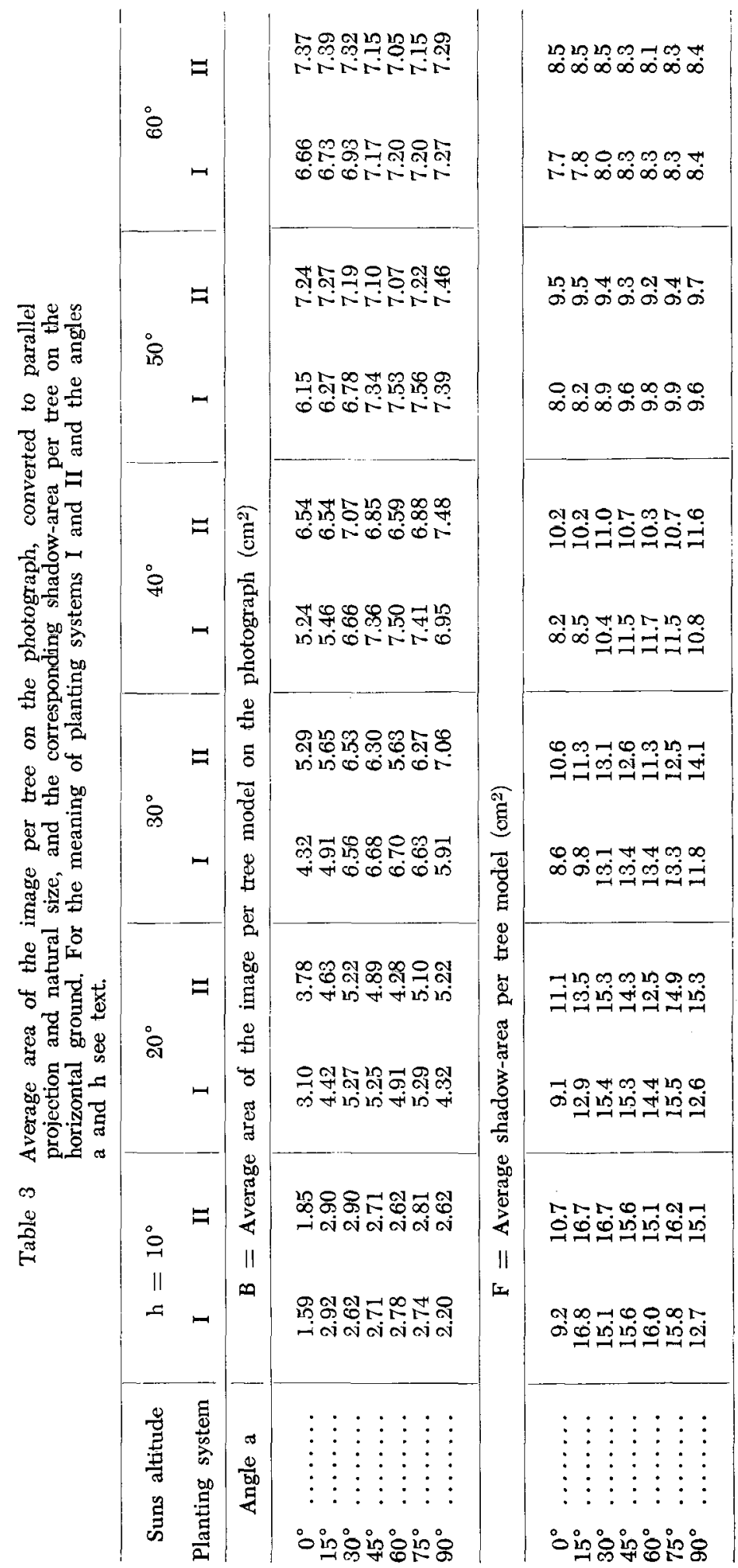


Table 4a Comparative amount of radiation intercepted by the trees, for different orientations of the rows.

$I=$ single row system, $I I=$ triangle-row system.

The amount of radiation for system I, orientation East-West, is 100.

\begin{tabular}{|c|c|c|c|c|c|c|c|c|c|c|c|c|}
\hline \multirow{2}{*}{$\begin{array}{l}\text { Orientation } \\
\text { of the rows }\end{array}$} & \multicolumn{2}{|c|}{ May } & \multicolumn{2}{|c|}{ June } & \multicolumn{2}{|c|}{ July } & \multicolumn{2}{|c|}{ August } & \multicolumn{2}{|c|}{ September } & \multicolumn{2}{|c|}{$\begin{array}{c}\text { May to } \\
\text { September }\end{array}$} \\
\hline & I & II & I & II & $\mathbf{I}$ & II & I & II & $\mathbf{I}$ & II & $\mathrm{I}$ & II \\
\hline & \multicolumn{12}{|c|}{ from sunrise to sunset: } \\
\hline East-West & 100 & 100 & 100 & 101 & 100 & 100 & 100 & 98 & 100 & 96 & 100 & 99 \\
\hline NE-SW & 99 & 101 & 100 & 103 & 100 & 102 & 95 & 98 & 93 & 95 & 98 & 100 \\
\hline North-South & 101 & 101 & 102 & 103 & 101 & 102 & 96 & 98 & 91 & 95 & 99 & 100 \\
\hline \multirow[t]{2}{*}{ NW-SE } & 99 & 101 & 101 & 103 & 100 & 102 & 95 & 98 & 93 & 95 & 98 & 100 \\
\hline & \multicolumn{12}{|c|}{ from sunrise to noon: } \\
\hline East-West & 100 & 100 & 100 & 100 & 100 & 100 & 100 & 98 & 100 & 96 & 100 & 99 \\
\hline NE-SW & 104 & 101 & 105 & 102 & 104 & 102 & 101 & 99 & 99 & 97 & 103 & 101 \\
\hline North-South & 100 & 101 & 102 & 103 & 101 & 102 & 96 & 98 & 91 & 95 & 98 & 100 \\
\hline \multirow[t]{2}{*}{ NW-SE } & 94 & 100 & 97 & 102 & 95 & 101 & 90 & 96 & 86 & 92 & 93 & 99 \\
\hline & \multicolumn{12}{|c|}{ from sunrise to noon and from 3 p.m. to sunset: } \\
\hline East-West & 100 & 101 & 100 & 102 & 100 & 101 & 100 & 99 & 100 & 97 & 100 & 100 \\
\hline NE-SW & 102 & 102 & 104 & 104 & 103 & 103 & 99 & 99 & 96 & 96 & 101 & 101 \\
\hline North-South & 102 & 102 & 105 & 105 & 104 & 103 & 99 & 99 & 93 & 95 & 101 & 101 \\
\hline NW-SE & 98 & 102 & 102 & 104 & 100 & 103 & 94 & 98 & 89 & 94 & 97 & 101 \\
\hline
\end{tabular}

Table 4b Amount of radiation for system I, orientation East-West, in cal/treemodel day. (Basic numbers in Table 4a).

\begin{tabular}{|c|c|c|c|c|c|}
\hline Period of the day & May & June & July & August & September \\
\hline $\begin{array}{l}\text { Sunrise to sunset } \ldots \\
\text { Sunrise to noon } \ldots \\
\text { Sunrise to noon and } \\
3 \text { p.m. to sunset. }\end{array}$ & $\begin{array}{l}4410 \\
2230 \\
3140\end{array}$ & $\begin{array}{l}4390 \\
2170 \\
3140\end{array}$ & $\begin{array}{l}4060 \\
1970 \\
2870\end{array}$ & $\begin{array}{l}3770 \\
1870 \\
\\
2570\end{array}$ & $\begin{array}{l}2930 \\
1510\end{array}$ \\
\hline
\end{tabular}

The weighted average shadow area appeared to be : for planting system I : $11,5 \mathrm{~cm}^{2}$ and for planting system II : $11,7 \mathrm{~cm}^{2}$.

To exemplify further computation we compute the amount of radiation received per tree for planting system I (trees in rows) with rows running East-West, during the hour from 8 to 9 a.m. (sun-time) in August.

From Table 2 we derive :

$$
\begin{gathered}
\mathrm{Q}_{\mathrm{z}}=20 \mathrm{cal} / \mathrm{cm}^{2} \mathbf{h} ; \quad \mathrm{Q}_{\mathrm{H}}=7 \mathrm{cal} / \mathrm{cm}^{2} \mathrm{~h} \\
\mathrm{~h}=33^{\circ} 26^{\prime} .
\end{gathered}
$$

The orientation-angle a, that is, the angle between the direction of the row and the direction of the sun (measured horizontally) is $30^{\circ}$ at 8 a.m. and $45^{\circ}$ at 9 a.m., the average value being $37^{\circ} 30^{\prime}$.

The shadow-area for unclouded sun, F, for this hourly period, is found from the values given in Table 3 by linear interpolation between the values:

$$
\begin{aligned}
& \mathrm{h}=30^{\circ}: \mathrm{a}=30^{\circ}, \mathrm{F}=13,1 \mathrm{~cm}^{2} ; \mathrm{a}=45^{\circ}, \mathrm{F}=13,4 \mathrm{~cm}^{2} . \\
& \mathrm{h}=40^{\circ}: \mathrm{a}=30^{\circ}, \mathrm{F}=10,4 \mathrm{~cm}^{2} ; \mathrm{a}=45^{\circ}, \mathrm{F}=11,5 \mathrm{~cm}^{2} .
\end{aligned}
$$


and appears to be $F=12.5 \mathrm{~cm}^{2}$. For the diffuse radiation the average shadow-area has the constant value of 11.5 as shown before.

Therefore the total global radiation received during this hour is :

$$
12.5 \times 20+11.5 \times 7=330 \mathrm{cal} / \mathrm{h}
$$

which goes for the tree-model. (For the real tree this would be $3.3 \times 10^{6} \mathrm{cal} / \mathrm{h}$ ).

These values have been computed for all hourly periods in each of the months May to September, for both planting systems, each in 12 different directions of the rows. Summation over the hours gives the amount of radiation which a tree receives during the day, or part of the day. As these figures have only a comparative value the results have been reproduced as indexnumbers, for which the value for direction of rows East-West, planting system I, is always 100. Table 4 a shows the results for 4 directions of the rows. Table $4 \mathrm{~b}$ gives the real values of the basic numbers.

\section{Discussion}

Radiation is the source of energy for photosynthesis. Moreover it promotes the colouring of the fruit. Fruits on the south side of the tree are generally better coloured than fruit on the north side. During the summer the products of assimilation are partly transformed into reserve-matter and therefore the amount of radiation received after harvest is still important for the general condition of the tree. The high production and the exceptionally good colour of the fruit in the sunny year 1959 has proved that in normal years the optimum of radiation is not reached in the Netherlands. So if it would be possible by using a certain planting system to increase the radiation energy for the trees, this would result in a better product.

No general answer can be given to the question whether radiation is equally effective during all hours of the day. It is possible that on very hot days, with a clear sky, photosynthesis decreases in the early afternoon. To account for this, radiation sums are given in Table 4 not only for the whole day, but also for the period from sunrise till noon, and for the whole day minus the period from noon to 3 p.m. On the whole planting system II (triangle-rows) appears to receive $1.3 \%$ more radiation than planting system I. This systematic difference can be ascribed to the fact that the ground area per tree in the former planting system is $3.7 \%$ more than in the latter.

In planting system II the direction of the rows appears to have only a slight effect on the quantity of radiation received. System I shows a much more substantial influence. In September, under the latter system, trees planted in rows running East-West receive $9 \%$ more radiation than trees in rows running North-South. In August this difference is $4 \%$. In June and July, however, the latter direction of the rows results in a slightly higher radiation, but here the difference is only 1 and $2 \%$, which may be neglected.

This seems to indicate that the direction East-West is to be preferred, especially for fruit ripening in September.

If the row-direction is pre-determined by the form of the field, the trianglerows might be preferable in cases where the direction is relatively unfavourable, for instance if the rows run from North to South or from Northwest to Southeast. If, however, the rows run East by West, there is hardly any preference for the planting system, as far as the radiation is concerned. 
The conclusion would be that there is no reason to believe that the trianglerow system yields more radiation per tree in all circumstances. If, however, a main direction of the rows is pre-determined, the proposed system might yield some more radiation under certain conditions.

Irrespective of the importance of the radiation factor amongst the various other factors which ultimately should lead to a decision on the planting system to be preferred, it is clear that for the single row planting system the direction of the rows has a marked effect on the amount of radiation received. It might be interesting to repeat this investigation for other planting systems and other forms of trees.

In the course of our study we thought about an alternative method to measure the combined shadow-area of a tree-stand. The first step would be to construct the shadow of a tree of any form on the ground for various sunaltitudes, after which the shadow of the stand should be drawn on a sheet of paper, according to the planting system and for a certain direction of the sun. The shadow of the stand thus acquired could be cut out and weighed, to estimate its surface. This should be repeated for different altitudes and directions of the sun and for the plantingsystems required. This would lead directly to the real area of the mean shadow per tree, i.e. the figures mentioned under $F$ in Table 3 . This method would save the labour required for making the wooden models. When we started our research the models were already available.

\section{REFERENCES}

BOER, H. J. DE : Calculation of global radiation in the Netherlands with the aid of relative duration of sunshine. To appear in: Archiv für Meteorologie, Geophysik und Bioklimatologie.

BraAk, C. : Het klimaat in Nederland, F : Zonneschijn en bewolking. Meded. en Verh K.N.M.I., 40 (1937) Tabel 9. 